\title{
The age at which adult height is achieved during adolescence in the Birth to Twenty Cohort, Johannesburg, South Africa
}

\author{
P N Ngcobo, ${ }^{1}$ FCPaed, Dip HIV Man; L H Nyati, ${ }^{2}$ MSc; $\mathbf{S}$ A Norris, ${ }^{2}$ PhD; J M Pettifor, ${ }^{2}$ PhD (Med), FCPaed (SA) \\ ${ }^{1}$ Department of Paediatrics, University of the Witwatersrand, Johannesburg, South Africa \\ ${ }^{2}$ MRC/WITS Developmental Pathways for Health Research Unit (DPHRU), Department of Paediatrics, Faculty of Health Sciences, University of \\ the Witwatersrand, Johannesburg, South Africa
}

Corresponding author: P N Ngcobo (nonhlengcobo@icloud.com)

\begin{abstract}
Background. The core of the study involves comparing the secular trends in height among self-reported black and white racial groups in South Africa (SA). The white group represents that part of the population that has always been affluent and therefore has growth trends comparable with those of developed nations of the world. In comparing the groups, we wanted to see the extent to which the black population has caught up, if it all, since the introduction of democracy in 1994.

Objectives. To establish the age at which linear growth plateaus; to compare the age of growth cessation and the achieved adult height between sexes and racial groups in SA; and to compare data from the Bone Health Cohort with previous similar studies to ascertain the secular trend.

Methods. We analysed prospective data of 569 individuals who had annual anthropometric assessments from age nine until 20 years (1999 - 2010). The SuperImposition by Translation and Rotation (SITAR) statistical programme was used to model height and age at growth cessation.

Results. There was a total of 183 black females, 93 white females, 205 black males and 88 white males. Black and white females achieved adult height at a similar age (15.1 and 15.3 years), but black females were $5.7 \mathrm{~cm}$ shorter. Black and white males achieved their adult height at 17.5 and 16.5 years, respectively, black males being $4.6 \mathrm{~cm}$ shorter. Mean adult black male height is currently $170.7 \mathrm{~cm} \mathrm{v.} 166.9 \mathrm{~cm}$ in 1971, while there were no significant secular changes in the other groups.

Conclusions. There has been a positive secular growth trend in height over 30 years among black males, but no changes in the other groups.
\end{abstract}

S Afr J Child Health 2021;15(2):60-66. https://doi.org/10.7196/SAJCH.2021.v15.i2.1686

James Tanner wrote: 'Human growth is a mirror of society; if you want to measure the classlessness of society, and you are not interested in rhetoric but in actual conditions and facts, then looking at the growth of children is perhaps the best way. ${ }^{[1,2]}$ Secular growth trends study the change in body size or composition in a given population over a long period. ${ }^{[3,4]}$ The study of secular trends in growth provides a reliable and an important assessment tool of the physical health of populations. It is also useful in highlighting social disparities between different groups of people. ${ }^{[4]}$ There are a host of factors involved in growth and its cessation in individuals. Secular growth trends, therefore, may be negative, positive or unchanged, depending on these factors. ${ }^{[3,4]}$ These factors can be divided into intrinsic or biological factors, and extrinsic or environmental factors; this means that, besides having a normal genotype, a child should grow in conditions conducive to good health, if optimal growth is to be achieved. One biological predictor of an individual's height is mid-parental height. Heterosis, the opposite of inbreeding, refers to increased capacity for growth of an offspring as a result of increased dissimilarity in the genetic makeup of parents. ${ }^{[5]}$ As more and more people from different ethnic and family backgrounds conceive children together, a positive change in secular trends occurs. In the South African (SA) context, particularly in Johannesburg, there is an influx of members of various tribal and ethnic groups. It is possible that heterosis could play some role in changing trends in the SA context.

Extrinsically the potential for growth is strongly influenced by socioeconomic, nutritional and health factors. ${ }^{[4,6]}$ Decreased family size and increased child spacing are associated with better care for the individual child, better maternal nutrition and therefore better chances of survival and growth. Changes in health practices and living conditions have an impact on mortality rates and life expectancy ${ }^{[5]}$ Although there remains much opportunity for improvement, major decisions have been taken by democratic government and civil organisations in SA aimed at improving implementation of these health strategies, which include the rolling out of programmes addressing household and school sanitation, awareness campaigns and health drives regarding women's rights and family planning, as well as many preventive strategies for diseases such as malnutrition, tuberculosis and HIV infection. Similarly, physical and mental stress can delay adolescence and be associated with a negative secular trend, as was seen after the 1992 - 1994 war in Croatia and Bosnia. ${ }^{[5]}$ Studies have investigated the role of adverse events on the neuroendocrine circuit, the role of adaptive responses to stress, and the long-term consequences of stress on the endocrine axes involved in the growth and pubertal development of individuals. ${ }^{[5]}$

The MRC/Wits Developmental Pathways for Health Research Unit has been recording the growth patterns of children from different racial backgrounds born during the democratic transitional period in the Johannesburg metropolitan region. A study in 2003 by Cameron concluded that the economic and social transition in the country had not resulted in improved child growth at that time. ${ }^{[7]}$

Our hypothesis was that although the legacy of inequality still prevails, there has been a change in the disparity in height between 
racial groups. We hypothesised that there was an improving secular trend in height among the black population while there was no change among the white population. Furthermore, the white population would achieve adult height earlier and their mean height would be greater than that of their black counterparts. The study also aimed to document the mean age at which adult height was achieved in the different groups.

\section{Methods}

The study was an analysis of prospectively collected longitudinal data, which was conducted in the MRC/Wits Developmental Pathways for Health Research Unit, Chris Hani Baragwanath Academic Hospital, Soweto, Johannesburg. It used data collected from 569 participants of the Bone Health Cohort, who had annual anthropometric measurements taken from nine until 20 years of age (1999 - 2010). The Bone Health Cohort is a sub-cohort, which was selected from the Birth to Twenty cohort, when the children were nine years of age, to study factors influencing pubertal development and bone acquisition during adolescence. The larger Birth to Twenty Study, from which the Bone Health Cohort was selected, is a longitudinal study of child health and development and comprised 2107 participants. The recruitment of eligible neonates $(N=3273)$ was done within a sevenweek period between 23 April and 8 June 1990.

Because of the demographics of births within the public health sector in Johannesburg, there was an insufficient number of white children in the Bone Health Cohort to provide adequate power for statistical analyses. To compensate, a supplementary sample of 226 white children, aged 10 years, who were born during the same period, was recruited from Johannesburg schools. The additional white children did not differ statistically from those enrolled at birth when considering characteristics such as maternal age, gestational age and birthweight. All children with chronic diseases (asthma, HIV and rheumatoid arthritis) likely to influence growth were excluded from the study.

All enrolled children were born within the metropolitan area of Johannesburg, SA, and were observed at yearly intervals. Trained research assistants using a stadiometer, which was checked regularly, measured the height of the children in light clothing and without shoes.

The following subject characteristics were extracted from the study records: study number, sex, ethnic group, and yearly height measurements including date of height measurement and age at height measurement date.

\section{Statistical methods}

Sample size was calculated using information obtained from a previous study, ${ }^{[8]}$ which reported the mean height of the SA adult population (Table 1). That study reported a $6.5 \mathrm{~cm}$ difference between black and white females, and a $7.8 \mathrm{~cm}$ difference between black and white males. To be able to detect a difference of $3 \mathrm{~cm}$ between black and white females and $5 \mathrm{~cm}$ between black and white males, an effective sample size of 104 participants was required for a level of significance of $5 \%$ with a power of $80 \%$.

As the Birth to Twenty Cohort size is over 500, we utilised data from the whole cohort to be able to detect a much smaller difference between the groups.

Annual height measurements were fitted using the SuperImposition by Translation and Rotation (SITAR) in R version 3.3.1 (Fig. 1). SITAR is a shape-invariant model with a single fitted curve that summarises individual growth patterns with three parameters, namely tempo (the timing of the onset of the pubertal growth spurt), size (the size of growth during puberty) and velocity (the rate of growth during the growth spurt). ${ }^{[9]}$
Table 1. Mean adult height among adult South Africans in $1971^{[8]}$

\begin{tabular}{ll}
\hline Group & Height $(\mathrm{cm})$, mean $(\mathrm{SD})$ \\
\hline Black female, $n=165$ & $158.9(5.34)$ \\
Black male, $n=186$ & $166.9(5.93)$ \\
White female, $n=151$ & $165.4(6.21)$ \\
White male, $n=152$ & $174.7(5.78)$ \\
$\mathrm{SD}=$ standard deviation. &
\end{tabular}

The coloured lines represent the individual curves adjusted for the SITAR parameters of size, tempo and velocity. The model extrapolates the figures beyond the minimum and maximum ages.

Age at growth cessation was determined as the age at which growth velocity decreased below $0.5 \mathrm{~cm}$ per annum. ${ }^{[10]}$

Data were analysed using Stata version 13.1 (Stata Corp., USA). Tests for normality were performed using skewness and kurtosis tests and were found to be satisfactory. To compare the age of growth cessation between sexes and subjects of different racial groups, analysis of variance (ANOVA) was used to compare mean ages between the four groups. An independent $t$-test was used to compare mean ages between racial groups within same-sex groups and between sexes of the same racial group. ANOVA was also used to compare mean heights between the four groups. Where data were not normally distributed, transformation was used. An independent $t$-test was used to compare mean heights between racial groups within same-sex groups and between sexes of the same racial groups.

\section{Ethics}

The proposal for this study was approved by the Graduate Studies Committee and ethics approval was obtained from the Human Research Ethics Committee (HREC) of the University of the Witwatersrand (ref. no. M160417). All information was obtained from participant records kept within the Research Unit. Written permission to utilise the data was obtained from the Unit Manager of the Research Unit. The subjects were identified by unique study numbers and not by name and address, thus maintaining participant confidentiality.

\section{Results}

There was a total of 183 black females, 93 white females, 205 black males and 88 white males in the Bone Health Cohort. Table 2 shows the mean height for each group at yearly intervals between 9 and 20 years. Black children were shorter than their white counterparts at all recorded ages. The table also shows the earlier pubertal growth spurt of females compared with males. Males grow for a longer period and reach a greater final height. Fig. 1 shows the individual height curves for all participants, with the mean curve shown as a white line. Figs 2A - D show the mean SITAR plots of the individual curves for mean height of participant groups by sex and race. Table 3 shows mean height and age at growth cessation for each group. Black females and white females had similar ages at which adult height was achieved (15.1 years v. 15.3 years; $p=0.1424$ ) (Figs $2 \mathrm{~A}$ and $2 \mathrm{~B}$; Table 3 ). The difference in height at growth cessation between black and white females was $5.7 \mathrm{~cm}(158.2 \mathrm{~cm}$ v. $163.9 \mathrm{~cm} ; p<0.0001)$ (Table 3).

At growth cessation, the mean height of black males was $170.7 \mathrm{~cm}$ and that of white males was $175.3 \mathrm{~cm}(p<0.0001)$ (Figs 2C and 2D;Table 3). White males achieved adult height at 16.5 years whereas black males achieved adult height at 17.5 years $(p<0.0001)$. The results of this study show that white children of both sexes reaching maturity were significantly taller by $\sim 5 \mathrm{~cm}$ 
than their black counterparts. White males reached their adult height more than a year later than their female counterparts and a year earlier than black males. These differences are statistically significant. Black females and white females had similar ages at which adult height was achieved (15.1 years in blacks and 15.3 years in whites). The decrease in height in the older age groups, as seen in Table 2, could be due to the smaller samples at ages 19 and 20, especially in white

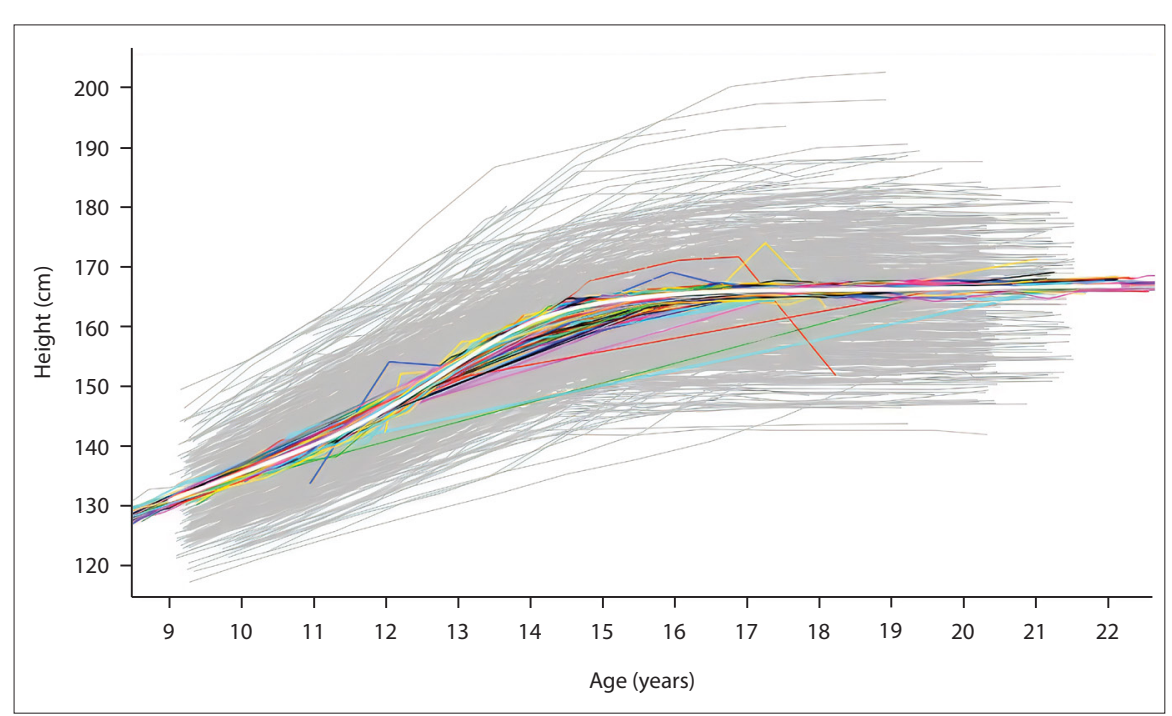

Fig. 1. The individual height curves for all participants, with the mean curve shown as a white line.

children. To address this, we combined the ages 18 - 20 into one age group of $18+$, which has improved the means.

\section{Discussion}

The pattern of secular changes in growth during childhood and adolescence has generally been positive during the past 50 - 100 years in Europe and the USA. Large increases in final adult height have occurred in all developed countries, but not
Table 2. Height by age in different groups in the Bone Health Cohort

\begin{tabular}{|c|c|c|c|c|}
\hline \multirow[b]{2}{*}{ Age, years } & \multicolumn{4}{|c|}{ Height $(\mathrm{cm}) ;$ mean $(\mathrm{SD})$} \\
\hline & Black females & White females & Black males & White males \\
\hline 9 & $\begin{array}{l}132.8(5.6) \\
131(39.6)\end{array}$ & $\begin{array}{l}136.1(6.8) \\
28(8.4)\end{array}$ & $\begin{array}{l}132.2(5.9) \\
146(44.1)\end{array}$ & $\begin{array}{l}137.2(6.0) \\
26(7.9)\end{array}$ \\
\hline 10 & $\begin{array}{l}139.2(6.2) \\
156(34.2)\end{array}$ & $\begin{array}{l}142.8(7.6) \\
61(13.4)\end{array}$ & $\begin{array}{l}137.4(6.2) \\
177(38.8)\end{array}$ & $\begin{array}{l}143.3(7.2) \\
62(13.6)\end{array}$ \\
\hline 11 & $\begin{array}{l}145.8(7.6) \\
156(33.3)\end{array}$ & $\begin{array}{l}148.1(8.0) \\
64(13.7]\end{array}$ & $\begin{array}{l}142.7(6.8) \\
179(38.3)\end{array}$ & $\begin{array}{l}148.2(7.7) \\
69(14.7)\end{array}$ \\
\hline 12 & $\begin{array}{l}151.4(6.8) \\
161(33.9)\end{array}$ & $\begin{array}{l}155.0(7.9) \\
68(14.3)\end{array}$ & $\begin{array}{l}147.4(7.8) \\
183(38.5)\end{array}$ & $\begin{array}{l}155.9(9.1) \\
63(13.3)\end{array}$ \\
\hline 13 & $\begin{array}{l}155.4(6.4) \\
150(35.0)\end{array}$ & $\begin{array}{l}160.3(6.8) \\
60(14.0)\end{array}$ & $\begin{array}{l}153.7(8.4) \\
170(39.6)\end{array}$ & $\begin{array}{l}164.0(9.9) \\
49(11.4)\end{array}$ \\
\hline 14 & $\begin{array}{l}157.4(6.0) \\
165(34.8)\end{array}$ & $\begin{array}{l}162.3(8.0) \\
72(15.2)\end{array}$ & $\begin{array}{l}160.1(8.6) \\
184(38.8)\end{array}$ & $\begin{array}{l}170.0(9.1) \\
53(11.2)\end{array}$ \\
\hline 16 & $\begin{array}{l}158.7(6.4) \\
164(35.5)\end{array}$ & $\begin{array}{l}164.5(6.6) \\
62(13.4)\end{array}$ & $\begin{array}{l}168.6(7.2) \\
183(39.6)\end{array}$ & $\begin{array}{l}176.9(7.7) \\
53(11.5)\end{array}$ \\
\hline 17 & $\begin{array}{l}159.3(6.3) \\
146(34.7)\end{array}$ & $\begin{array}{l}165.3(6.8) \\
57(13.5)\end{array}$ & $\begin{array}{l}170.3(6.7) \\
172(40.9)\end{array}$ & $\begin{array}{l}178.0(8.7) \\
46(10.9)\end{array}$ \\
\hline 18 & $\begin{array}{l}159.4(6.1) \\
124(37.9)\end{array}$ & $\begin{array}{l}166.3(7.1) \\
30(9.2)\end{array}$ & $\begin{array}{l}171.2(6.6) \\
137(41.9)\end{array}$ & $\begin{array}{l}178.0(8.0) \\
36(11.0)\end{array}$ \\
\hline 19 & $\begin{array}{l}158.9(6.5) \\
50(30.3)\end{array}$ & $\begin{array}{l}164.2(6.9) \\
32(19.4)\end{array}$ & $\begin{array}{l}170.0(6.8) \\
55(33.3)\end{array}$ & $\begin{array}{l}177.2(9.1) \\
28(17.0)\end{array}$ \\
\hline 20 & $\begin{array}{l}158.9(5.9) \\
127(43.0)\end{array}$ & $\begin{array}{l}164.5(6.7) \\
15(5.1)\end{array}$ & $\begin{array}{l}171.3(6.9) \\
136(46.1)\end{array}$ & $\begin{array}{l}174.3(6.8) \\
17(5.8)\end{array}$ \\
\hline
\end{tabular}

in many developing countries. ${ }^{[11,12]}$ SA, being a developing country with a long history of socioeconomic and political inequalities, has trends that have shown patterns of both developed and developing regions. The section of the population that was always affluent has maintained a positive trend similar to that of countries where there are no socioeconomic constraints.

In 1978, Richardson ${ }^{[13]}$ reviewed data on the physical size of 14087 children from a variety of SA studies. The mean heights and weights of white children began to diverge from those of their non-white peers by two years of age. The poorest growth was seen among rural black children, and the best among urban white children. There was some variation by age, but the consistent hierarchy, from smallest to largest, was black rural, black urban, mixed ancestry urban, Indian urban and white urban. ${ }^{[14]}$

The previously disadvantaged population, which has always lagged behind, has in recent years shown an improving growth trend. A recent review found significant secular advances in skeletal maturity between 1962 and 2001 in urban black SA male children. ${ }^{[14]}$ No noteworthy change was seen among white children over the same period. The secular advances in skeletal maturity in black children were consistent 


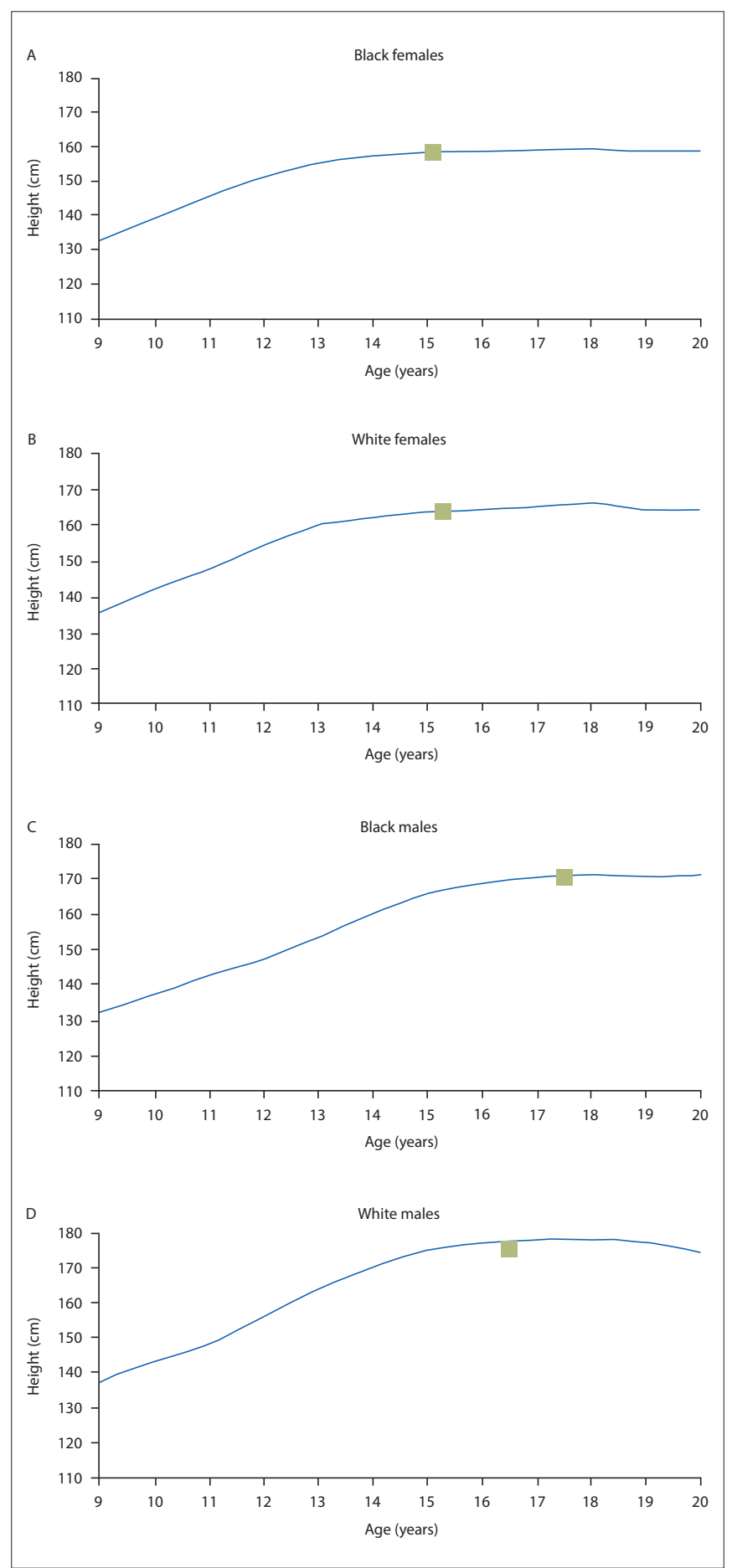

Fig. 2. Mean curve for height showing maximum height and age at growth cessation for (A) black females, (B) white females, (C) black males, and (D) white males. with increases in their height and adiposity. ${ }^{[14]}$ The authors concluded that the increase in skeletal maturity might be the result of the removal of growth constraints in black children. ${ }^{[14]}$

Adult black males are now on average $3.8 \mathrm{~cm}$ taller than in 1971 (170.7 cm compared with $166.9 \mathrm{~cm}$ in 1971) $(p<0.0001)$, while there is only a non-significant difference of $0.6 \mathrm{~cm}$ in height between the present cohort of adult white males and those measured in 1971 (175.3 cm compared with $174.7 \mathrm{~cm}$ in 1971) $(p=0.5141)$ (Tables 1 and 3). No change in height was found in black or white females between current cohorts and those measured over 40 years previously (black females currently $158.2 \mathrm{~cm} \mathrm{v.} 158.9 \mathrm{~cm}$ in 1971) ( $p=0.2578)$ (white females currently $163.9 \mathrm{~cm} \mathrm{v} .165 .4 \mathrm{~cm}$ in 1971) ( $p=0.0814$ ) (Tables 1 and 3 ). Therefore, there has only been a positive secular trend in the black male group.

The results of the present study raise some interesting questions. Why do black and white females have the same age at height cessation, a finding not present in black and white males? If females stop growing at the same age, why are females of the two racial groups not the same size? The answers may lie in differences in the interplay between a number of factors including onset and duration of puberty, skeletal maturation, menarche, heredity and poverty.

\section{Age at growth cessation}

Establishing the age at which growth ceases highlights an important landmark in human development and provides a reference for historic and future comparisons for a population. In humans, longitudinal bone growth and, hence, linear growth ceases in late adolescence. ${ }^{[15]}$ The cessation of growth marks the biological onset of adulthood. It is, however, not the end of development; development of physical prowess, skill and mental processes continues for many years. ${ }^{[16]}$ Females stop growing earlier than males and this sex difference in the age of growth cessation is common across many populations.

The pubertal growth spurt is characterised by rapid changes in bone length, mass and structure as adolescents undertake the final stretch to adult height. During this time, growth in height accelerates, then peaks, and finally falls to zero. ${ }^{[17]}$ The timing and rate of this pubertal growth spurt is highly variable between individuals and is partially determined by heredity. ${ }^{[18]}$ Hawley et al. ${ }^{[14]}$ found that skeletal maturation can be a useful tool in comparing and predicting growth as the secular trends in skeletal maturation were concordant with secular change in stature. They also found that there had been a positive secular trend in skeletal maturation among the black male group compared with older studies even though skeletal maturation had been delayed among the black male group compared with their white counterparts. In a SA study published in 2015, skeletal maturity was reached 1.9 years earlier in girls than in boys, and the pattern of maturation differed between the sexes. Among girls, there were no ethnic differences in the pattern or timing of skeletal maturity. Among boys, however, skeletal maturity was delayed by seven months in those of black compared with white ethnicity. ${ }^{[19]}$ Males tend to grow for a longer time as they start their height acceleration later than females. As Table 2 illustrates, there is significant catch-up

Table 3. Mean height and age at growth cessation of the Bone Health Cohort

\begin{tabular}{lllll}
\hline Characteristics & Black females & White females & Black males & White males \\
\hline Number of participants/observations, $n / N$ & $183 / 1679$ & $93 / 605$ & $205 / 1889$ & $88 / 557$ \\
Height at growth cessation (cm), mean (SD) & $158.2(6.1)$ & $163.9(7.0)$ & $170.7(6.7)$ & $175.3(8.4)$ \\
Age at growth cessation (years), mean (SD) & $15.1(1.1)$ & $15.3(1.0)$ & $17.5(1.3)$ & $16.5(1.1)$ \\
SD = standard deviation. & & & &
\end{tabular}


growth from the age of $14-17$ in males while females stop growing at 15 years of age.

A study in the same cohort looking at age at menarche, found that the median menarcheal age for blacks was 12.4 years (95\% confidence interval (CI) 12.2 - 12.6) and 12.5 years (95\% CI 11.7 - 13.3) for whites. ${ }^{[20]}$ There was no difference in the age of onset of puberty and menarche between black and white females. Black females enter puberty and menarche with a shorter stature, compared with their white counterparts (Figs 2A and 2B; Table 2). There is no catch-up growth during the pubertal growth spurt in black females (Table 2). The final result is a shorter height at growth cessation for black females. Ultimately, black and white females have the same age at height cessation because of similar age at menarche, yet their final sizes differ, as black females are consistently shorter than white females in the prepubertal period.

\section{Height at growth cessation}

The significance of adult height has been studied extensively in various disciplines, and has far-reaching consequences relating to the health, economic, psychological and social aspects of an individual.

Many studies have found a positive correlation between short stature and prevalence of cardiovascular disease while others find evidence that taller people have a higher risk of cancer. ${ }^{[21]}$ The adverse effects of short stature during pregnancy, childbirth and child rearing are well established. ${ }^{[22]}$ There is no consensus about the effect of height on longevity.

Tall stature is also a proxy for social status and leadership in both men and women, which includes higher earning potential, dominance in interpersonal interactions, and success in attracting a desired partner in the case of men. ${ }^{[22]}$

Moreover, positive secular change in height highlights improvements in health and social conditions in transitional countries such as SA. In a neighbouring country, significant positive changes in growth and nutritional status were observed among Mozambican youth from 1992 to 2012, which were associated with economic, social and cultural developments. ${ }^{[23]}$ Another study that analysed youths at age 15.5 years in Seychelles in 2005/6 found a positive secular trend in final height when compared with published data from 1956/7.[24] Both studies concluded that the change in trends was due to general improvement of living conditions of the population. ${ }^{[23,24]}$

\section{Study limitations}

Because of the demographics of births within Johannesburg, there was an insufficient number of white children in the smaller cohort to provide adequate power for statistical analyses. To compensate for this shortfall, a supplementary sample of 226 white children aged 10 years born during the same period was recruited from Johannesburg. Furthermore, as race was self-declared, heterosis, which has been occurring for the last few centuries in SA, might have had a genetic influence on cessation of growth and final height, and that is difficult to measure.

\section{Conclusion}

The age at which adult height is reached among both black and white females in Johannesburg, SA, is just over 15 years. Among males, adult height is achieved at means of 16.5 and 17.5 years, respectively, with white males reaching it before black males. Secular growth trends in height in SA show a positive change among black males. Future studies may ascertain the continuation of positive secular trend changes in height among the black section of the population.

Declaration. The present manuscript is submitted in partial fulfilment of the requirements for the MMed (Paeds) degree at the University of the Witwatersrand.

Acknowledgements. Special thanks to the DPHRU staff.

Author contributions. JMP, PNN and SAN conceptualised the study. PNN wrote the manuscript. All authors were co-investigators in the study. LHN performed the statistical analysis. JMP directed the study methods. All authors reviewed and contributed to drafting the manuscript.

Funding. None.

Conflicts of interest. None.

1. Tanner JM. Growth as a mirror of the condition of society: Secular trends and class distinctions. Acta Paediatr J 1987;29(1):96-103. https://doi.org/10.1111/ .1442-200x.1987.tb00015.x

2. Tanner JM. Growth as a mirror of conditions in society. In: Lindgren GW, editor Growth as a Mirror of Conditions in Society. Stockholm: Institute of Education Press, 1990:9-48.

3. Malina RM. Research on secular trends in auxology. Anthropol Anz 1990;48:209-227.

4. Vargas DM, Arena LFGL, Soncini AS. Secular trend of growth in height in Blumenau, Brazil, and its relationship with the human development index (HDI). Rev Ass Med Bras 2010;56(3):304-308. https://doi.org/10.1590/s0104 42302010000300014

5. INSERM Collective Expertise Centre. INSERM Collective Expert Reports 2007 Growth and Puberty Secular Trends, Environmental and Genetic Factors. Paris: INSERM, 2007. https://www.ncbi.nlm.nih.gov/books/NBK10786/ (accessed June 2015).

6. Monteiro CA, Conde WL. Secular trends in postnatal growth in S. Paulo city, Brazil (1974 - 1996). Rev Saúde Pública 2000;34(6):41-51. https://doi. org/10.1590/s0034-89102000000700007

7. Cameron N. Physical growth in a transitional economy: The aftermath of South African apartheid. Econ Hum Biol 2003;1(1):9-42. https://doi.org/10.1016/ s1570-677x(02)00008-4

8. Van de Wal BW, Erasmus LD, Hechter R. Stem and standing heights in Bantu and white South Africans: Their significance in relation to pulmonary function values. S Afr Med J 1971;45(21):568-570.

9. Cole TJ, Donaldson MD, Ben-Shlomo Y. SITAR - a useful instrument for growth curve analysis. Int J Epidemiol 2010;39(6):1558-1566. https://doi.org/10.1093/ije/ dyq115

10. Carrascosa A, Ferrandez A, Audi L, Sanchez E. Pubertal growth and adult height according to age at pubertal growth spurt onset: Data from a Spanish study including 540 subjects ( 281 boys and 259 girls). In: Preedy V, ed. Handbook of Growth and Monitoring in Health and Disease. New York: Springer, 2012:1525 1544. https://doi.org/10.1007/978-1-4419-1795-9 90

11. Roche AF. Secular trends in human growth, maturation, and development Monogr Soc Res Child Dev 1979;44(3/4):3-27. https://doi.org/10.2307/1165883

12. Malina RM. Secular trends in growth, maturation and physical performance: A review. Anthropol Rev 2004;67:3-31.

13. Richardson BD. Growth patterns of South African children. S Afr J Sci 1978;74:246-249.

14. Hawley NL, Rousham EK, Norris SA, Pettifor JM, Cameron N. Secular trends in skeletal maturity in South Africa: 1962 - 2001. Ann Hum Biol 2009;36(5):584594. https://doi.org/10.1080/03014460903136822

15. Nilsson O, Baron J. Fundamental limits on longitudinal bone growth: Growth plate senescence and epiphyseal fusion. Trends Endocrinol Metab 2004;15(8):370 374. https://doi.org/10.1016/s1043-2760(04)00185-7

16. Rauber A. Growth and development. In: Walker HK, Hall WD, Hurst JW, eds. Clinical Methods: The History, Physical and Laboratory Examinations. 3rd ed. Boston: Butterworths, 1990.

17. Rauch $F$. The dynamics of bone structure development during pubertal growth. J Musculoskelet Neuronal Interact 2012;12(1):1-6.

18. Dubois L, Ohm Kyvik K, Girard M, et al. Genetic and environmental contributions to weight, height and BMI from birth to 19 years of age: An international study of over 12000 twin pairs. PLoS ONE 2012;7(2):e30153. https://doi.org/10.1371/ journal pone.0030153

19. Cole TJ, Rousham EK, Hawley NL, Cameron N, Norris SA, Pettifor JM Ethnic and sex differences in skeletal maturation among the Birth to Twenty cohort in South Africa. Arch Dis Child 2015;100:138-143. https://doi:10.1136/ archdischild-2014-306399 
20. Jones LL, Griffiths PL, Norris SA, Pettifor JM, Cameron N. Age at menarche and the evidence for a positive secular trend in urban South Africa. Am J Hum Biol 2009;21(1):130. https://doi.org/10.1002/ajhb.20836

21. Samaras TT. How height is related to our health and longevity: A review. Nutr Health 2013;21(4):247-261. https://doi.org/10.1177/0260106013510996

22. Stulp G. Sex, stature, status: Natural selection on height in contemporary human populations. Groningen: University of Groningen/UMCG Research Database, 2013:302

23. Dos Santos FK, Maia JAR, Gomes TNQF, et al. Secular trends in growth and nutritional status of Mozambican school-aged children and adolescents. PLoS ONE 2014;9(12):e114068. https://doi.org/10.1371/journal.pone.0114068
24. Marques-Vidal P, Madeleine G, Romain S, Gabriel A, Bovet P. Secular trends in height and weight among children and adolescents of the Seychelles, 1956 - 2006. BMC Public Health 2008;8:166. https://doi.org/10.1186/14712458-8-166

Accepted 4 November 2020 